\title{
Evaluation of antioxidant activities by use of various extracts from abutilon pannosum and grewia tenax in the kachchh region
}

\begin{abstract}
Abutilon pannosum (AP) and Grewia tenax (GT) is a significant medicinal plant widely used in the kachchh region against several diseases. This study was devoted to the determination of antioxidant activity of A. pannosum and G. tenax leaf. Determination of antioxidant activity (AOA) after their successive soxhlet extraction using various solvents with different polarities like n-hexane, benzene, chloroform, acetone, ethyl acetate, acetonitrile and ethanol and also petroleum ether, isopropanol, methanol and water. In the present study following findings were observed: (i) Determination of the AOA in different solvent leaf extracts (DSE) of AP and GT by 2, 2-diphenyl-1picrylhydrazyl (DPPH), total antioxidant capacity (TAC) by the phosphomolybdenum method (PM) and 2, 2-azinobis-(3-ethylbenzothiazoline-6-sulphonate) (ABTS) method. All these AOA increased with increasing concentrations in a quantity dependent method. The AOA was measured with IC50 values of the extracts ranged between AP: $0.338 \mu \mathrm{g} / \mathrm{ml}$ to $1.460 \mu \mathrm{g} / \mathrm{ml}$ and GT: $0.023 \mu \mathrm{g} / \mathrm{ml}$ to $0.652 \mu \mathrm{g} / \mathrm{ml}$. IC50 values is contrariwise proportional to the AOA of plant extracts. The lowest IC50 revenues had the maximum antioxidant capacity. The maximum radical scavenging effect was detected in AP (with IC $50=0.338 \mu \mathrm{g} \mathrm{ml} / 1$ by methanolic fraction of ethyl acetate) and GT (with IC $50=0.023 \mu \mathrm{g} / \mathrm{ml}$ by the methanolic fraction of acetone). We conclude after the some contact interval there were no significant change could be shown in some types of sample extract. The data obtained in the present study suggests that the different solvent extract and its methanolic fraction of AP and GT leaves have potent antioxidant activity against free radicals, prevent oxidative damage to major biomolecules and afford significant protection against oxidative damage in the liver.
\end{abstract}

Volume 5 Issue I - 2017

\author{
Mital K Aadesariya,' 'Vijay R Ram,' Pragnesh \\ N Dave ${ }^{2}$
}

'Department of Chemistry, KSKV Kachchh University, India

${ }^{2}$ Department of Chemistry, Sardar Patel University, India

\section{Correspondence: Pragnesh N Dave, Department of}

Chemistry, Sardar Patel University, Vallabh Vidyanagar-388 I20

(Gujarat), India, Tel 989826249I, Email pragnesh7@yahoo.com

Received: July 19, 2017 | Published: September 26, 2017

Keywords: abutilon pannosum, grewia tenax, DPPH, TAC, PM, ABTS, different solvent extract, methanolic extract, antioxidant activity

Abbreviations: AP, abutilon pannosum; GT, grewia tenax; AOA, antioxidant activity; DSE, different solvent leaf extracts; DPPH, 2-diphenyl-1- picrylhydrazyl; TAC, total antioxidant capacity; PM, phosphomolybdenum method; ABTS, 2-azinobis-(3ethylbenzothiazoline-6-sulphonate); SET, single electron transfer; HAT, hydrogen atom transfer; EA, ethyl acetate; ACN, acetonitrile; $\mathrm{EtOH}$, ethanol; AC, acetone; IP, isopropanol; W, water; $\mathrm{MF}$, methanolic fraction

\section{Introduction}

Medicinal plants that have a significant amount of Phytochemicals like phenolic compounds, polyphenols, flavonoids and alkaloids have been described to have multiple biological effects, including antioxidant activity. ${ }^{1}$ In modern times, there has been an increase in the use of medicinal plants for therapeutic antioxidant agents. ${ }^{2}$ An antioxidant may be defined as 'any substance that when present at low concentrations, compared with those of the oxidizable substrate significantly delays or inhibits oxidation of that substrate, but later defined them as "any substance that delays, prevents or removes oxidative damage to a target molecule" or Antioxidant is a molecule that inhibits the oxidation of other molecules. ${ }^{3}$ Natural antioxidants are known to exhibit a wide range of biological effects including antibacterial, antiviral, anticancer, anti-inflammatory, ant allergic, antithrombic and vasodilatory activities. Antioxidant activity gives rise to Anticarcinogenicity, ant immunogenicity and antiaging activity. ${ }^{4-7}$

Current studies have revealed that there is no worldwide method to evaluate the antioxidant activity quantitatively and precisely, $5,7,8$ therefore, the AOA of plants is assessed using numerous procedures. These procedures differ in terms of their assay principle and investigational situations. Utmost of them are based on the study of a reaction in which a free radical is produced and how this reaction is repressed by the accumulation of the compound or sample which is the object of the measurement of antioxidant capacity. ${ }^{9}$ The effect of the antioxidant activity of the samples differs rendering of the nature of the solvent used and predominantly to the methods of investigation. ${ }^{10}$ The presence of different antioxidant components in the plant sample makes it relatively hard to quantify each antioxidant component separately. Therefore, in many studies, several intermediate extractions are used to ensure a maximum extraction of the available antioxidants. ${ }^{11}$

In present work anti-oxidant activity of two medicinal plant $A$. pannosum and $G$. tenax leaf extracts were evaluated with use of different solvent according to their polarity (like n-hexane, benzene, chloroform, acetone, ethyl acetate, acetonitrile and ethanol and also petroleum ether, isopropanol, methanol and water respectively) by using DPPH, TAC and ABTS. These methods are illustrious by their mechanism of action and would be corresponding to the work of the 
antioxidant potential of plants. In addition, all extracts were further fractionated by using methanol with reflux through the condenser. After that methanolic fractions were again used for AOA by use of two methods (DPPH and TAC) for evaluation of plant sample activity. Methanol solvent was used in the partition and separation of the various metabolites of different polarity solvents extract as per their solubility. The prospective antioxidant activity of fractions and also different extract which exhibited good antioxidant activity that fraction and extract was also being done using different concentration assays and compared with known antioxidants (Ascorbic acid).

\section{Materials and methods}

\section{Antioxidant activity}

In the present work antioxidant activity of $A$. pannosum and $G$. tenax leaf extracts evaluated after successive soxhlet extraction by mainly three methods DPPH, ABTS, TAC (phosphomolybdenum method). Successive extraction was a well technique to extract the antioxidants from medicinal plants than other techniques. ${ }^{12}$

DPPH Method: DPPH is stable free radical at room temperature, the reduction capability of DPPH radical is determined by the decrease in its absorbance at $517 \mathrm{~nm}$, induced by antioxidants. The decrease in absorbance of DPPH radical is caused by antioxidants, since of the reaction between antioxidant molecules and radicals, improvements, which results in the scavenging of the radical by hydrogen donation. It is visually perceptible as a change in color from purple to yellow. Hence, DPPH is generally used as a substrate to evaluate the AOA. ${ }^{13,14}$

Principle: The free radical scavenging activity of the extract was measured in terms of hydrogen donating or radical scavenging ability using the stable free radical DPPH. Determination of DPPH radical scavenging activity was estimated by the method used by Blois. ${ }^{15}$ It offers an accurate and convenient method for determining antioxidant capacity due to the relatively (Figure 1) short time required for analysis. The methanolic solution of DPPH is a stable radical which shows peak absorbance at $518 \mathrm{~nm}$. The absorbance disappears due to the reduction of 2, 2'-diphenyl-1-picrylhydrazyl radical (purple color solution) to 2, 2'-diphenyl-1- picrylhydrazine (yellow color solution). ${ }^{16}$

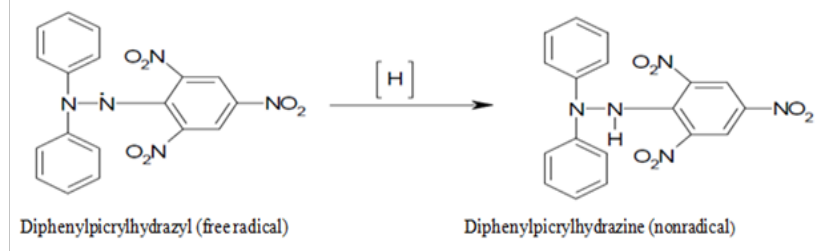

Figure I Reduction of free radical by DPPH.

Procedure: $1 \mathrm{mM}$ solution of DPPH in ethanol and also $1 \mathrm{mg} / 1 \mathrm{ml}$ extract solution in ethanol was prepared and $1.5 \mathrm{ml}$ of this solution was added to $1.5 \mathrm{ml}$ of DPPH. The absorbance was measured at $517 \mathrm{~m}$ against the corresponding blank solution which is prepared by taking $3 \mathrm{ml}$ ethanol and control O.D. was prepared by taking $3 \mathrm{ml}$ of DPPH. The assay was achieved in triplicates. Ratio inhibition of free radical DPPH was calculated based on control reading by the succeeding equation.

\section{Calculation}

$$
\text { DPPH scavenged }(\%)=\frac{\left(A_{\text {control }}-A_{\text {test }}\right)}{A_{\text {control }}} \times 100
$$

Where,

A control - is the absorbance of the control reaction

A test - is the absorbance in the presence of the sample of the extracts. ${ }^{17-20}$

ABTS Method: The Antioxidant activity of the samples was measured by ABTS (2, 2-azino-bis (3-ethylbenzthiazoline- 6-sulfonic acid) radical cation decolourization assay according to the method of Re et al, (1999). ${ }^{21}$

Principle: ABTS radical scavenging assay comprises a process that generates a blue/green/blues green ABTS + chromophore through the reaction of ABTS and potassium persulfate. The ABTS radical cation is produced by the oxidation of ABTS (Figure 2) with potassium persulfate, reduction capability of ABTS radical is determined by the decrease in its absorbance since hydrogen donating at $734 \mathrm{~nm}$, induced by antioxidants. It is visible as a change in color from dark bluish green to colorless. ${ }^{22}$

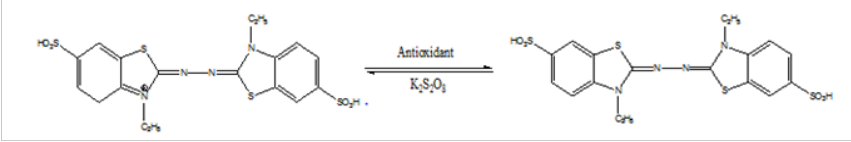

Figure 2 Depicts the formation of ABTS as a result of reaction between ABTS and potassium persulfate and the scavenging of the radical cation so formed using ABTS and. Scavenging assay.

Procedure: ABTS•+ was formed by reacting $7 \mathrm{mM}$ ABTS aqueous solution with $2.4 \mathrm{mM}$ Potassium Per sulphate in the dark situation for 12-16hour at room temperature. Previous to assay this solution was diluted in ethanol (about $1: 89 \mathrm{v} / \mathrm{v}$ ) and equilibrated at $30^{\circ} \mathrm{C}$ to give an Absorbance at $734 \mathrm{~nm}$ of $0.700 \pm 0.02$. Later the addition of $1 \mathrm{ml}$ of diluted ABTS solution to $10 \mu \mathrm{l}$ of test sample in ethanol absorbance was measured at $30^{\circ} \mathrm{C}$ accurately $30 \mathrm{~min}$. after the early mixing. The inhibition percentage was calculated for the blank absorbance at $734 \mathrm{~nm}$. Radical scavenging activity was expressed as the inhibition percentage of free radical by the sample and was calculated via the following formula.

\section{Calculation}

$$
\text { ABTSscavenged }(\%)=\frac{\left(A_{\text {control }}-A_{\text {test }}\right)}{A_{\text {control }}} \times 100
$$

Where,

A control-is the absorbance of the control reaction

A test-is the absorbance in the presence of the sample of the extracts

Preparation of $7 \mathbf{m M}$ ABTS solution: Dissolve $8 \mathrm{mg}$ ABTS in $1 \mathrm{ml}$ 
water (Solution A). Dissolve 13.2mg Potassium Per sulphate in $10 \mathrm{ml}$ water (Solution B). Mix $0.5 \mathrm{ml}$ solution A and $0.5 \mathrm{ml}$ solution B above and allow to stand in Dark at room temperature for about 12-16hour before use. The concentration of ABTS and Potassium Per sulphate are in the mixture and $7 \mathrm{mM}$ and $2.45 \mathrm{mM}$ respectively. The ABTS radical cation in this form is stable for at least 12 -16hours.

\section{Total antioxidant activity}

The propensity of plant extract and fractions to diminish molybdate ion was determined according to the technique given by Prieto et al. ${ }^{23}$ The phosphomolybdenum method is routinely applied in the laboratory to evaluate the total antioxidant capacity of plant extracts. ${ }^{23}$

Principle: The antioxidant capacity of the sample was measured spectrophotometrically through phosphomolybdenum method, based on the reduction of Mo (VI) to Mo (V) by the test sample and the subsequent formation of bluish green phosphate/Mo (V) compounds with a maximum absorption at 695NM. The phosphomolybdenum method is quantitative one to determine the antioxidant activity in terms of reduction of molybdate ions (Figure 3). The antioxidant activity is expressed in terms of ascorbic acid equivalents as ascorbic acid is used to plot a standard curve. ${ }^{24}$

$$
\begin{aligned}
& \mathrm{Mo}^{+6}+\mathrm{A} \rightarrow \mathrm{MO}^{+5}+A_{\text {oxidized }} \\
& \mathrm{Mo}^{+5}+? \mathrm{PO}_{4}^{3-} \stackrel{95^{\circ} \mathrm{C} \text { tempcrature } 90 \mathrm{~min} \mathrm{MO}_{3}\left(\mathrm{PO}_{4}\right)_{5}}{\longrightarrow} \text { Greencolorcomplex }\left(\lambda_{\max }=695 \mathrm{~nm}\right)
\end{aligned}
$$

Figure 3 Mechanism of action involved in molybdate reduction assay.

Procedure: The sample $0.3 \mathrm{ml}$ at different concentration was mixed with $3 \mathrm{~mL}$ of reagent solution $0.6 \mathrm{M} \mathrm{H}_{2} \mathrm{SO}_{4} 28 \mathrm{mM}$ sodium phosphate and $4 \mathrm{mM}$ ammonium molybdate. The tubes were covered and incubated in a thermal block at $95^{\circ} \mathrm{C}$ for $90 \mathrm{~min}$. Once cooling at room temperature $\left(28^{\circ} \mathrm{C}\right)$, the absorbance of the aqueous solution of all was measured at $695 \mathrm{~nm}$ against a blank. Ascorbic acid at different concentration was used as the standard and the total antioxidant capacity is stated as equivalent of ascorbic acid.

\section{Preparation of reagent solution}

a) $28 \mathrm{mM}$ sodium phosphate: It was ready by dissolving $3.35 \mathrm{~g}$ of sodium phosphate in $1 \mathrm{~L}$ of distilled water.

b) $4 \mathrm{mM}$ ammonium molybdate: $4.94 \mathrm{~g}$ of ammonium molybdate was dissolved in $1 \mathrm{~L}$ of distilled water.

c) $\mathbf{0 . 6 \mathrm { M }}$ of sulphuric acid: $33.33 \mathrm{ml}$ of concentrated (18N) sulphuric acid was added to distilled water to make up the final volume of the reagent to $1 \mathrm{~L}$. The ascorbic acid was taken as standard and standard curve was obtained using $300-1000 \mu \mathrm{g} / \mathrm{ml}$ concentrations.

$\mathrm{TAC}$ reagent $\rightarrow$ Mix $(\mathrm{A}+\mathrm{B}+\mathrm{C})$ solution equal volume to make a reagent solution.

The regression equation obtained for ascorbic acid was $\mathrm{y}=0.2175 \mathrm{x}+0.1476 \quad\left(\mathrm{R}^{2}=0.9965\right)$; Here, $\mathrm{y}=$ absorbance obtained at $695 \mathrm{~nm}$ and $\mathrm{x}=$ concentration of ascorbic acid used. The reduction ability or antioxidant activity of extracts and different fractions was stated in terms of mg Ascorbic Acid Equivalents (AAE)/100mg dry weight of extract or fractions as calculated from the standard curve found for ascorbic acid.

\section{Result and discussion}

In the present investigation antioxidant activities of different solvent extracts (DSE) and its methanolic fractions (MFE) of A. pannosum and G. tenax leaf extracts were studied. Different polarity extracts like n-hexane, benzene, chloroform, acetone, ethyl acetate, acetonitrile and ethanol and also petroleum ether, isopropanol, methanol and water and its methanolic fractions of two plants leaves of AP and GT were subjected to antioxidant screening against the DPPH radical, ABTS radical cation and TAC (phosphomolybdenum), because this assays have been widely used to determine the free radical-scavenging activity of various pure compounds or extracts. The ability of different solvent extraction and their methanolic fraction to reduce free radicals was measured by using UV-VIS spectrophotometry. Different solvents dissolve different bio compounds due to differences in their polarity. The factors affecting the choice of solvent are; quantity of Phytochemicals to be extracted, the rate of extraction, the diversity of different compounds extracted, ease of subsequent handling of the extracts, toxicity of the solvent in the bioassay process and potential health hazard of the extract. ${ }^{25}$

Antioxidant capacity calculates might be generally confidential as single electron transfer (SET) and hydrogen atom transfer (HAT) based assays. Preponderances of HAT assays like DPPH and ABTS are kinetics based and include an economical reaction system in which antioxidant and substrate contend for free radicals thermally generated through the disintegration of azo compounds. SET assays measure the capacity of an antioxidant in the reduction of an oxidant which changes colour when reduced. SET assays are easier than HAT assays. SET assays like Phosphomolybdenum (PM) were certain to analyse the reduced capacity. The antioxidant activity of phenolic is mainly due to their redox properties, which allow them to act as reducing agents, hydrogen donators, and singlet oxygen quenchers. ${ }^{26}$

When an antioxidant scavenges the free radicals by hydrogen donation (HAT), the color in the DPPH and ABTS assay solutions become lighter and TAC assay involves an electron transfer (SET) mechanism thus solution become color (dark greenish blue) ${ }^{27}$

According to Pérez-Jiménez et al. ${ }^{28}$ the type of solvent and polarity may affect the single electron transfer and the hydrogen atom transfer, which are key aspects in the measurement of antioxidant capacity. ${ }^{28}$ In DPPH method there is a loss of colour deep purple to yellow colour due to radical react directly with an antioxidant which absorbs light at $518 \mathrm{~nm} .{ }^{29}$ In TAC by phosphomolybdenum method there is a affinity of extract and fractions to gain color light yellow to dark greenish blue due to reduced molybdate ions in phosphomolybdenum complex at $695 \mathrm{~nm}$. It was stated in terms of number of Ascorbic Acid Equivalents (AAE) in $\mathrm{mg} / 100 \mathrm{mg}$ dry weight of extract or fractions as calculated from the standard curve attained for ascorbic acid ${ }^{30}$ and in ABTS [2, 2'-azinobis-(3-ethylbenzothiazoline-6- sulphonate)] radical cation $(\mathrm{ABTS} \bullet+)$ method there is a reducing of dark blue colour due to oxidation by peroxyl radicals or other oxidants originates the radical cation $\mathrm{ABTS} \bullet+$ thus, they can act as reducing agents and hydrogen donators at $734 \mathrm{~nm}$. ABTS also known as TEAC (Trolox Equivalent Antioxidant Capacity) assay. ${ }^{31}$ Wang et al. ${ }^{31}$ found that 
some compounds which have ABTS+ scavenging activity did not show DPPH scavenging activity. ${ }^{32}$ Antioxidant activity depends on the number and position of the hydroxyl groups on the aromatic ring binding site and the type of substitute. Regarding to results, the capacity of the polyphenols to act as antioxidants not only depends on the redox properties of their phenolic hydroxyl groups and the potential for electron delocalization across the chemical structure, as also of the possible reactivity of the reaction products formed during the reaction with DPPH, phosphomolybdenum and ABTS. For this reason, some authors consider that this contribution of the reaction products to the radical scavenging activity limits those methods to evaluate structure-activity relationship as well as correlate the results with the antioxidant activity obtained by other methods. ${ }^{33}$ The antioxidant activities correlated with the concentration, chemical structures, and polymerization degrees of sample. ${ }^{34}$

In fact ABTS, TAC and DPPH methods used in the present work, it is very tough to describe the results gained in three methods, hence there is no correlation of activities between the three methods. The antioxidant activity of standards was measured using a spectrophotometric method based on UV-Vis absorption spectroscopy techniques. The graph was plotted against concentration $v s$ absorbance at different wavelength according to the method, resulting in a linear relationship as shown in Figure 4-6. Linear regression analysis of DPPH, TAC and ABTS resulted in a correlation coefficient $\left(\mathrm{R}^{2}\right)$ of $0.9994,0.9965$ and 0.9985 respectively. The resultant standard curve (Figures 4-6) can then be interpolated for determination of antioxidant capacity of unknown samples and reported as their standard equivalent.
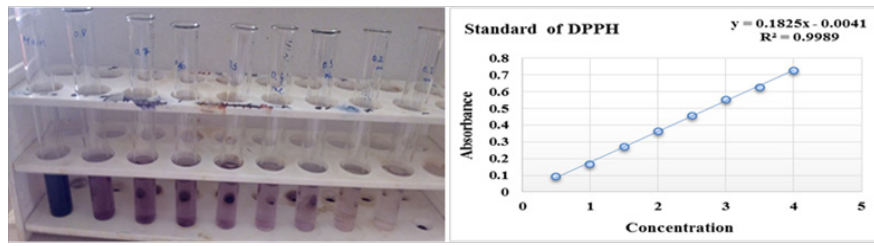

Figure 4 Standard of DPPH.
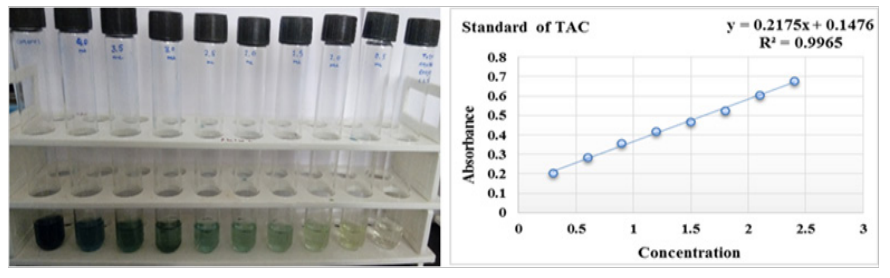

Figure 5 Standard calibration curve of TAC (Phoshomolybdenum) method.
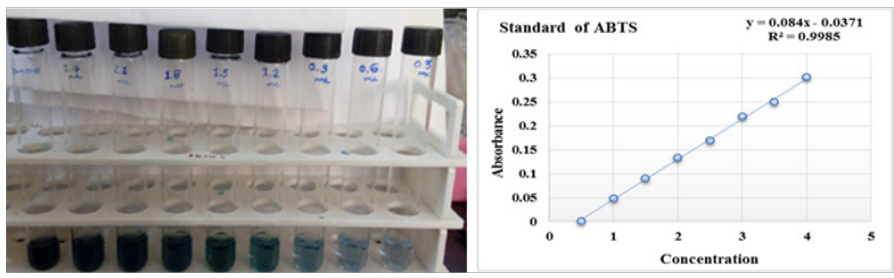

Figure 6 Standard calibration curve of ABTS method.

\section{Antioxidant activity of A. pannosum and G. tenax plant leaves extract in different solvents by DPPH,TAC (PM) and ABTS method6}

DPPH: From the methodological point of view the DPPH $\bullet$ method is recommended as easy and accurate with regard to measuring the antioxidant activity of plant extracts. The results are highly reproducible and comparable to other free radical scavenging methods such as ABTS. ${ }^{35}$ DPPH radical scavenging activity increased with increasing phenolic components such as flavonoids, phenolic acids and phenolic diterpenes. These phenolic constituents have several hydroxyl groups, containing an o-dihydroxy group which have very strong radical scavenging effect and antioxidant power. ${ }^{36}$ Decrease in absorbance shows the more efficient antioxidant activity of the extract in terms of hydrogen atom donating capacity. The antioxidants present in an extract of leaves of G. tenax and A. pannosum was able to diminish the violet color stable 2, 2-diphenyl-1-picrylhydrazyl radical to the yellow color 2,2-diphenyl-1-picrylhydrazyl. This may be due to the neutralization of free radicals (DPPH), either by transfer of hydrogen atoms or by transfer of an electron. ${ }^{37}$ The effect of different solvent extract of DPPH radical scavenging activity was observed and shown in Figure 7. In this study, results exhibited that G. tenax has good antioxidant activity compare to A. pannosum. In the assay, free radical scavenging activity was found to be in order of acetone $>$ ethyl acetate>ethanol>acetonitrile extract showed higher activity in $G$. tenax and ethanol>acetonitrile>ethyl acetate $>$ acetone extract showed strong antioxidant activity in A. pannosum and other solvent contain less amount of scavenging ability. This means phytochemicals soluble in moderate polar solvent possess a stronger potential to scavenge DPPH free radicals. Aqueous plant extracts had not revealed any antioxidant activity with this assay and organic extracts had exposed very stimulating results. The antioxidant proprietors of extracts were measured in terms of their efficient $\mathrm{IC}_{50}$ concentration consistent to the sample concentration that condensed the initial DPPH $\bullet$ absorbance of $50 \%$. These $\mathrm{IC}_{50}$ values are given in Table 1 .

Phosphomolybdate (TAC): The phosphomolybdate method is quantitative; therefore the total antioxidant capacity (TAC) (Figure 8) is stated as ascorbic acid equivalent. The capacity of methanol extracts and their fractions to condense molybdate ions was measured by taking ascorbic acid as standard. $0.3-2.4 \mathrm{mg} / \mathrm{ml}$ concentrations of ascorbic acid were used to attain standard curve and the regression equation gained for ascorbic acid was $y=0.2175 x+0.1476\left(R^{2}=0.9965\right)$; Here, $\mathrm{y}=$ absorbance found at $695 \mathrm{~nm}$ and $\mathrm{x}=$ concentration of ascorbic acid used. The current study confirmed that $G$. tenax revealed the supreme antioxidant capacity compare to $A$. pannosum. Only petroleum ether and acetonitrile extract of AP exhibited higher A.O activity compare to petroleum ether extract of $G$. tenax. The radical scavenging activity decreased in the following order

cetonitrile $>$ acetone $>$ ethyl $>$ acetate $>$ ethanol $>$ petroleumether $>$ water $>$ benzene $>$ isopropanol $>$ dichloromethane $>$ chloroform in the AP plants leaf extract and methanol $>$ ethanol $>$ acetone $>$ acetonitrile $>$ water $>$ benzene $>$ ethyl acetate $>$ petroleum ether $>$ isopropanol $>$ dichloro $>$ meth ane $>$ n-hexane $>$ chloroform in the GT plant leaf extracts. According to the result in the both plants contain good A.O activity in polar solvent $i$. e. ethanol, methanol, acetonitrile, acetone etc. Recent work has shown 
that many flavonoid and related polyphenols contribute expressively to the phosphomolybdate scavenging activity of medicinal plants. ${ }^{38}$

ABTS Radical scavenging assay: The decolorization of the $\mathrm{ABTS} \bullet+$, through measuring the reduction of the radical cation as the percentage inhibition of absorbance at $734 \mathrm{~nm} .{ }^{21}$ ABTS •+ was generated by incubating (Figure 9) ABTS $\bullet+$ chromophore through the reaction. ${ }^{36}$ The perceived antioxidant of extracts may be due to the neutralization of radical (ABTS), (Table 2) either by transfer of hydrogen atoms or transfer of an electron, ${ }^{39}$ The radical scavenging activity decreased in the following order ethyl acetate $>$ water $>$ acetonitrile $>$ methanol $>$ petroleum $>$ mether $>$ benzene $>$ acetone $>$ ethanol $>$ isopropanol $>$ hexane $>$ chloroform in $A$. pannosum plants leaf extract and ethanol $>$ acetonitrile $>$ ethyl acetate $>$ methanol $>$ acetone $>$ water $>$ isopropanol $>$ hexane $>$ benzene $>$ petroleum ether $>$ chloroform in the $G$. tenax plant leaf extracts.

\section{Antioxidant activity of A. pannosum and G. tenax plant leaves methanolic fraction extract of different solvents by DPPH and TAC (PM) method}

After studying the free radical scavenging effect of a different polarity solvent extract of both plant leaves by the use of above derive three methods, further all extracted fractioned by using methanol with reflux through the condenser, that methanolic fractions again used of for check scavenging ability of crude extract against free radical. In this assay performed by use of two method DPPH and TAC for evaluated of plant sample activity.

DPPH: The DPPH scavenging activity of different methanolic fractions of leaves of A. pannosum and G. tenax are shown in Figure 10. The ethyl acetate methanolic fraction (EAMF) showed highest DPPH radical scavenging activity in A. pannosum whereas acetone methanolic fraction (AMF) exhibited highest DPPH radical scavenging activity in $G$. tenax at $1 \mathrm{mg} / \mathrm{ml}$ concentrations. While water and chloroform showed the lowest amount of radical scavenging activity in AP and GT. The radical scavenging activity in the A. pannosum plant leaves extracts decreased in the following order of ethyl acetate $(86.30 \%)$, acetonitrile (81.38\%), ethanol (78.66\%), acetone (73.95\%), isopropanol (67.36), Petroleum ether (62.66\%), n-hexane (61.92\%), benzene $(51.78 \%)$, methanol $(32.01 \%)$, chloroform $(31.80 \%)$ and water $(0.21 \%)$ and $G$. tenax plant leave extracts decreased in the following order of acetone $(90.48 \%)$, Ethyle acetate $(89.85 \%)$, acetonitrile $(89.12 \%)$, Water $(87.76)$, ethanol $(78.45 \%)$, Petroleum ether $(73.01 \%)$, methanol $(64.33 \%)$, n-hexane $(68.10 \%)$, benzene $(50.73 \%)$ and chloroform (42.26\%).

Total antioxidant capacity of the phosphomolybdnum method (PM): PM method measures the reduction degree of Mo (VI) to Mo (V). These methods are involved in the mechanism of single electron transfer system. In this system electron from oxidized antioxidant moved to the substrate by inhibiting oxidation of oxidant. PM method is based on the redox antioxidant reaction is to assess the reduced concentration of Phosphate-Mo (VI). PM assay gives an instant result of a great range of separate antioxidants in dose-response way. Higher degree of color creation designates the more reducing power of analyte. It is Simple, reproducible investigation. ${ }^{29}$

PM assay is a quantitative method to consider the reduction reaction rate mid antioxidant, oxidant and molybdenum ligand (Table 3 ). It includes in thermally producing auto-oxidation during lengthy incubation period at higher temperature. It gives a direct estimation of reducing the capacity of antioxidant. So it shows individuality among in vitro antioxidant assays. ${ }^{40}$ The total antioxidant capacity (TAC) of different methanolic fractions of leaves of $A$. pannosum and G. tenax are shown in Figure 11. The methanol extract of both plants has very good reducing power and chloroform extract of both plants showed very poor reducing capacity. A. pannosum in the reducing capacity of samples could be observed as well: methanol $>$ dichloromethane $>$ benzene $>$ acetonitrile $>$ ethanol $>$ hexane $>$ ethyl $>$ acetate $>$ petroleum $>$ ether $>$ acetone $>$ water $>$ isopropanol $>$ chloroform and G. tenax in the reducing capacity showed as well: methanol $>$ ethanol $>$ acetone $>$ isopropanol $>$ hexane $>$ benzene $>$ dichloromethane $>$ acetonitrile $>$ petroleum ether $>$ ethyl acetate $>$ water $>$ chloroform. The antioxidant activity of extracts is strongly dependent on the solvent due to the different antioxidant potentials of compounds with different polarity. ${ }^{41,42}$ It has been reported that in plant compounds with different polarity and structure are present that dissolve in specific solvents having similar polarity. ${ }^{43,44}$

\section{Comparison between different solvent extract and its methanolic fraction of A. pannosum and G. tenax plant leaves by DPPH and TAC (PM) method}

The antioxidant activity result of the different solvent extracts and its methanolic fraction for two medicinal plants A. pannosum and $G$. tenax were obtained. In the present assay comparison between DSE and its MFE. In DPPH method MFE of all extract obtained from a different solvent crude extract exhibited higher antioxidant activity comparable to that DSE, Thus, this might be due to the fact that crude of DSE have a tendency to more interfering substances as compared to fractions. ${ }^{37}$ While the contrary result showed in TAC (PM), DSE exposed higher adsorption compare to its MFE, except of n-hexane, petroleum ether, dichloromethane. This may due to DSE have more interfering substances so that compound formed complex structure via thermal process. That result solution color appears to become dark green. Thus, in TAC different solvent crude extract showed higher values compared to its methanolic fraction. The result shown in Table $2 \&$ Table 3 and also in Figure 12-14.

The results of the present investigation demonstrate that a methanol could be increases of different solvent crude extract efficiency toward scavenging ability of free radicals. Only methanol extract existed weak antioxidant activity while the methanol fraction of different crude extract provided stronger antioxidant activity. The results designate that methanolic fractions found from different solvent crude extract display higher antioxidant activities as associated to the only methanol solvent extract. This could be due to the fact that crude (methanol) extract tends to have more interfering substances as compared to fractions. ${ }^{45}$ The results obtained of TAC that a DCE were shown higher absorption compare that of MFE but only methanol extract existed a very higher absorption capacity compare to other solvent extract in both plants. This may due to methanol consist hydroxyl group which is mainly responsible for the increase antioxidant capacity. ${ }^{46}$

IC50 of DPPH scavenging activity of A. pannosum and G. tenax leaf different solvent extract and its methanolic fraction which exhibited well AOA

The antioxidant activities of the plant extract were determined on 
the base of the free radical scavenging influence of stable DPPH free radical. ${ }^{47}$ The reaction mixture $(3.0 \mathrm{~mL})$ consisting of $1.5 \mathrm{~mL}$ DPPH $(1 \mathrm{mM}), 1.5 \mathrm{~mL}$ diverse concentrations (30 to $150 \mu \mathrm{g} / \mathrm{ml}$ ) of DSE was incubated for $10 \mathrm{~min}$, in the dark, after which the absorbance was measured at $517 \mathrm{~nm}$ using a UV-VIS Spectrophotometer (Shimadzu, Japan). The absorbance of each solution was determined, the corresponding blank readings were also taken and remaining DPPH was calculated. Decrease in absorbance illustrations the more competent antioxidant activity of the extract in terms of hydrogen atom donating capacity. This assay is more indirect type as it measures the inhibition of reactive species (free radicals) produced in the reaction mixture and its results depend on the type of reactive species use. ${ }^{48}$

The scavenging activity was stated as $\mathrm{IC}_{50}(\mu \mathrm{g} / \mathrm{ml})$. The $\mathrm{IC}_{50}$ was used to categorize the quality of the antioxidants in the sample extracts that compared to standard. It was perceived that, the DPPH radical scavenging activity of the tested extracts amplified with the quantity of plant material in the extract. $\mathrm{IC}_{50}$ of DPPH scavenging activity is the concentration of sample or standard that can prevent $50 \%$ of DPPH scavenging activity. $\mathrm{IC}_{50}$ values are contrariwise proportional to the antioxidant activity of plant extracts. The lowest $\mathrm{IC}_{50}$ means had the highest antioxidant capacity. The sample that has an IC50 fewer than $50 \mu \mathrm{g} / \mathrm{ml}$ is a very strong antioxidant, $50-100 \mu \mathrm{g} / \mathrm{ml}$ is a strong antioxidant, $101-150 \mu \mathrm{g} / \mathrm{ml}$ is a medium antioxidant, whereas $\mathrm{IC}_{50}$ greater than $150 \mu \mathrm{g} / \mathrm{ml}$ is a weak antioxidant. ${ }^{49} \mathrm{IC}_{50}$ values were calculated by applying suitable regression analysis of the mean inhibitory values of DPPH radical. Figure 21 shows the concentration dependent response curve of DPPH scavenging activities of the different solvent crude extract and methanolic fractions of leaves of AP and GT. The DPPH solution without sample solution was used as a control. $\mathrm{IC}_{50}$ values are the concentration of a sample $(\mathrm{mg} / \mathrm{ml})$ required to scavenge $50 \% \mathrm{DPPH}$ free radical and was calculated from inhibition curve. ${ }^{50}$

The current study revealed that $\mathrm{IC}_{50}$ of DPPH scavenging activities of ethyl acetate (E. A), acetonitrile (ACN) ethanol (EtOH), acetone (A.C), isopropanol (I.P), water (W) and its methanolic fraction (M.F) of leaf extracts of A. pannosum and G. tenax. In this study, results showed that all samples had significant levels of radical scavenging activity (Figure 15). According to the results exhibited that antioxidant capacity for all the extracts were found in the range of 0.338 to 1.460 in A. pannosum and 0.0232 to 0.652 in G. tenax thus, $G$. tenax contained highest antioxidant activity compare to $A$. pannosum and also showed that the methanolic fraction of different solvent extract gives very strong antioxidant activity comparable to that solvent extract fraction. The highest radical scavenging activity was shown by a methanolic acetone extract fraction of $G$. tenax by the low $\mathrm{IC}_{50}$ value of $\mathrm{IC}_{50}=0.0232 \mathrm{mgml}^{-1}$ which is higher than other all extracts and acetone leaves extract of $A$. pannosum showed lowest
DPPH radical scavenging activity, as described by high $\mathrm{IC}_{50}$ values of $\mathrm{IC}_{50}=1.460 \mathrm{mg} / \mathrm{ml}$ and $\mathrm{IC}_{50}$ values of standard graph $273.995 \mathrm{mg} /$ $\mathrm{ml}$ was observed. The radical scavenging activity in the A. pannosum and $G$. tenax plant extracts decreased in the following order M.F.E.A $>$ M.F.ACN $>$ M.F.EtOH $>$ EtOH $>$ M.F.A.C $>$ M.F.I.P $>$ ACN $>$ E. $\mathrm{A}>$ A.C and M.F.A.C $>$ M.F.E.A $>$ M.F.ACN $>A C N>$ E. A $>$ M.F.W $>$ M. F. EtOH $>$ EtOH $>$ A.C, respectively. All of A. pannosum and G. tenax leaves extracts with different polarity solvents (Acetone extract, isopropanol extract, ethyl acetate extract, Milli-Q- water extract, acetonitrile extract, ethanol extract and its methanolic fraction extract) can be categorized as very strong and a strong antioxidant. It has well established that free radical scavenging activity of plant extracts is mainly due to flavonoids, carotenoids and phenolic compounds. ${ }^{51}$ Further work is essential to find the components in phenolic and flavonoids that may have contributed to the greater antioxidant activity. ${ }^{52}$

\section{Effect of time on scavenging activity of A. pannosum and G. tenax leaf methanolic fractions obtained from a different solvent crude extract by DPPH method}

The time is the most important factor affecting to the compounds antioxidant capacity. ${ }^{53}$ Time of reaction also produced diverse results thus; in present part we were focused on the effect of time depend factor on different methanolic fraction extract like ethyl acetate, acetonitrile, ethanol and acetone. In industry, time is a very important factor to be enhanced even in order to diminish energy rate of the process. ${ }^{54}$ The effects of time on the antioxidant capacity of APMF and GTMF extract were revealed in Figure 16-23. The sample extract was estimated at same time difference 30,60, 90 and 120minutes. Generally, 30 minutes of reaction provided lower scavenging activity compare to 120 minutes. That means AOA was increased as the time increased. The maximum AOA was shown, in order of MFEA (89.6\%), MFACN (85.2\%), MFEtOH $(76.6 \%)$ and MFAC $(70.5 \%)$ was achieved in 120minutes in AP and MFAC (96.7 \%), MFEA (93.9\%), MFACN (90.7\%), and MFEtOH (89.5\%) was attained in 120minutes in GT. This may be due to the Scavenging (Table 4) ability of sample extract against free radical an increased with increased time as a certain limit. According to the result of AOA none major differences between 90 and 120minutes. This showed that the prolonged time do not significantly enhance the antioxidant activity of the extracts. This finding was related to the Fick's second law of diffusion, which indicated that the solute concentration in the plant matrix will achieve final equilibrium with the bulk solution over a certain period of time..$^{55}$ Furthermore, the extreme course of period will cause degradation of phenolic compounds due to light and oxygen exposure leading to the phenolic oxidation. ${ }^{56}$ Which may have responsible for reduce AOA power thus, the time of 90 and 120 minutes were favourable for good result.

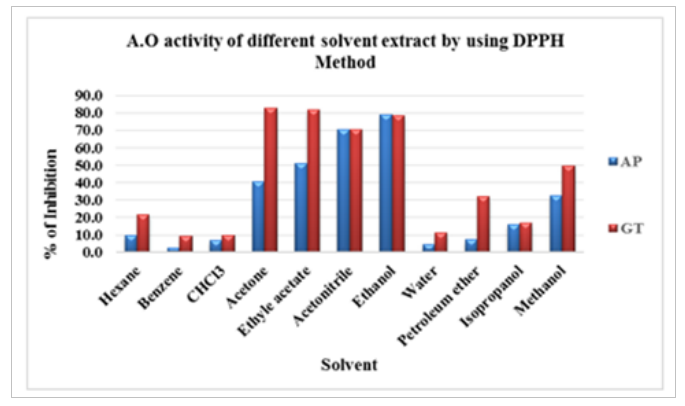

Figure 7 Free Radical Scavenging effect of different solvent extract by DPPH method. 


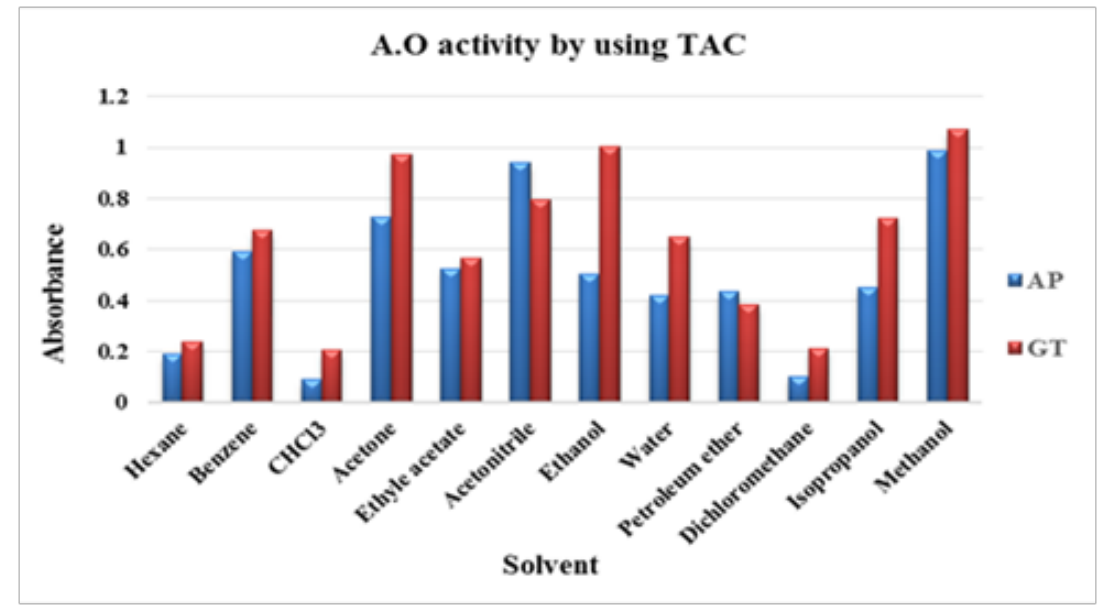

Figure 8 Free radical reducing effect of different solvent extract by TAC method.

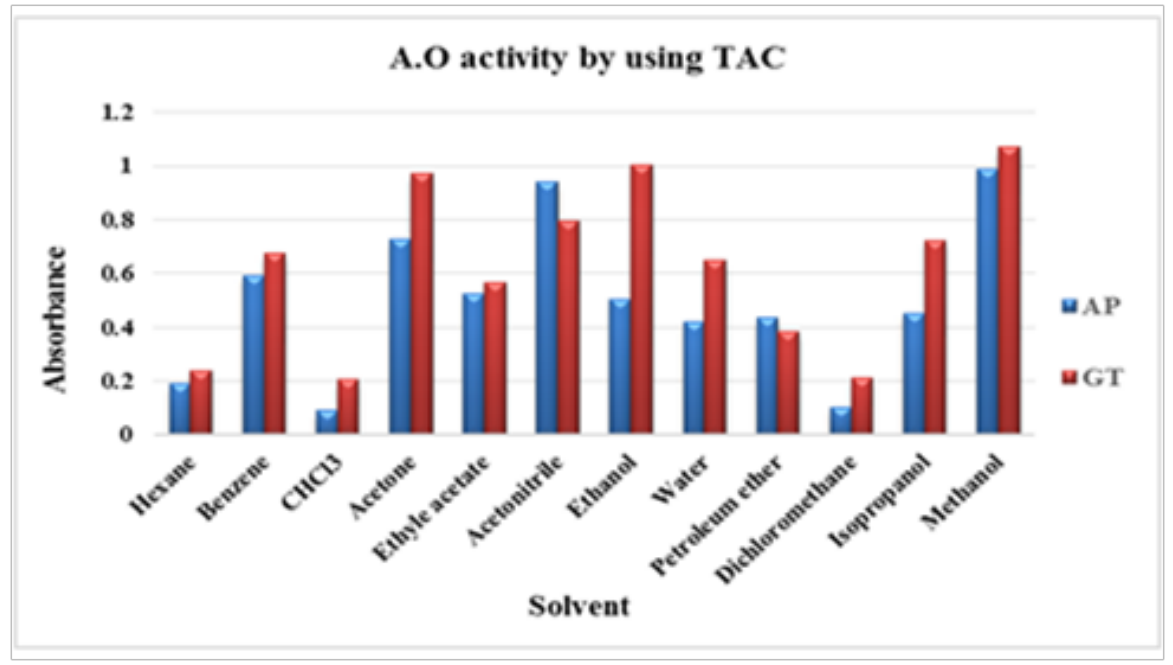

Figure 9 Free radical scavenging effect of different solvent extract by ABTS method.

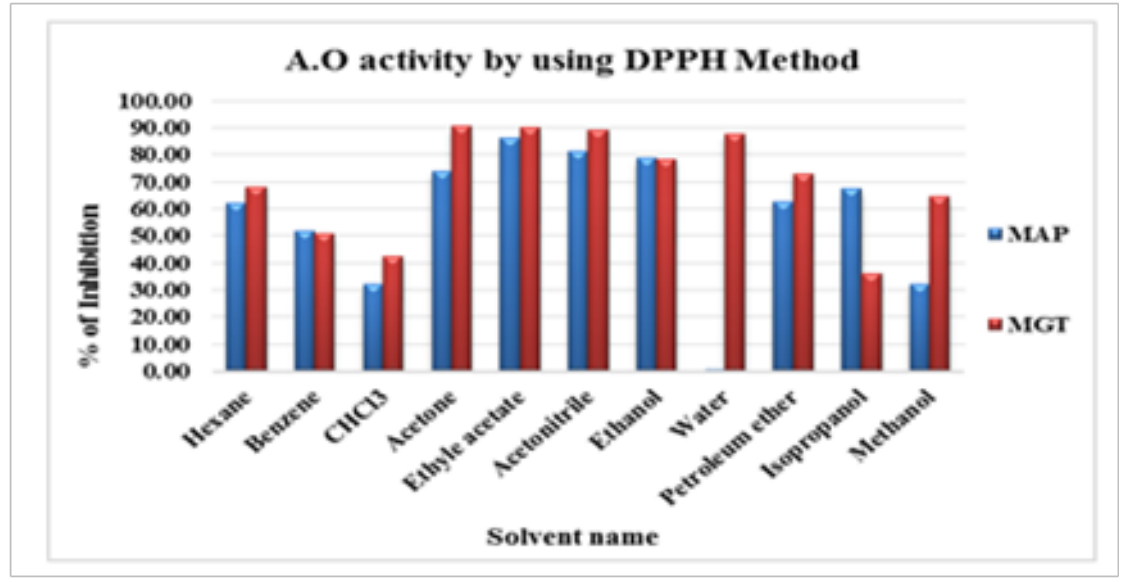

Figure 10 A.O activity of methanolic fraction of different solvent leaves extract of A. pannosum and G. tenax. 


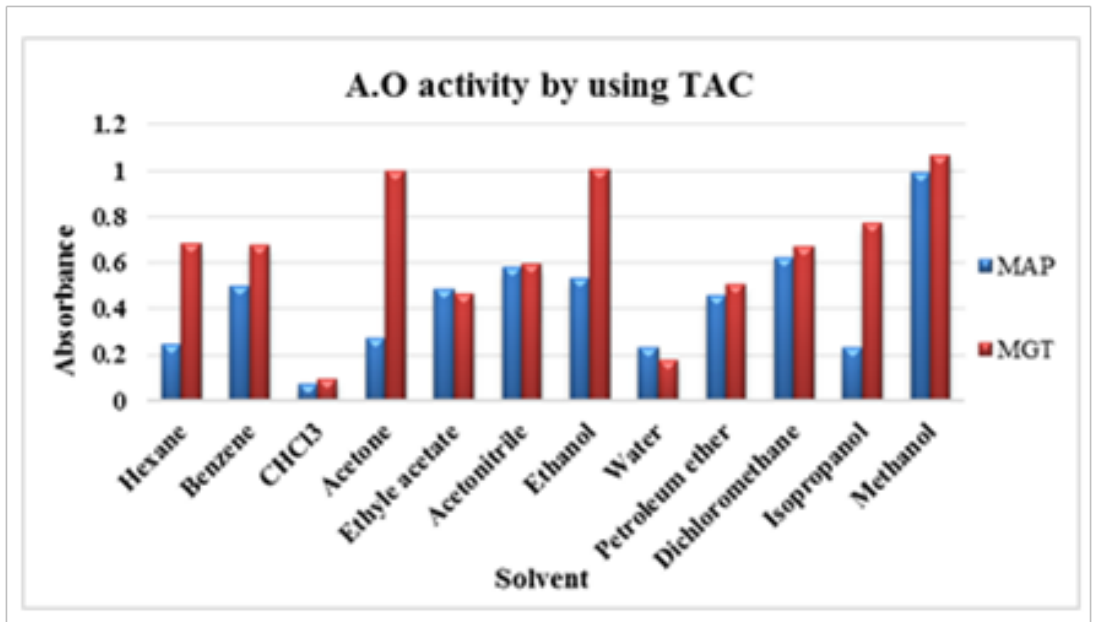

Figure I I A.O activity of methanolic fraction of different solvent leaves extract of A. pannosum and G. tenax by TAC method.

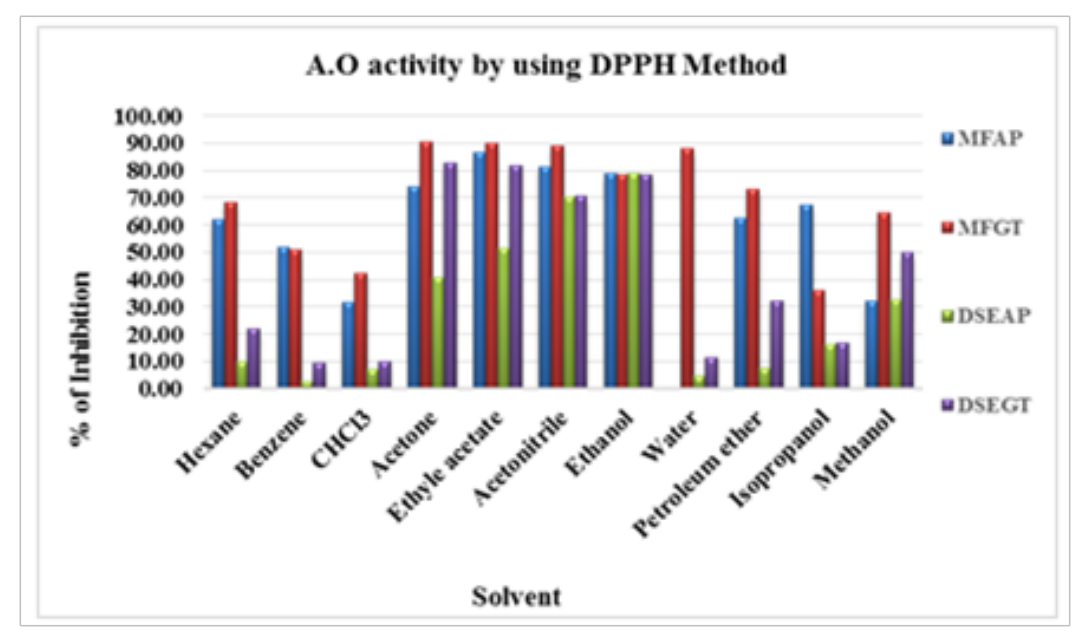

Figure 12 Comparison between different solvent extract and its methanolic fraction by DPPH method [DSEAP=Different solvent extract of A.pannosum, DSEGT=Diifferent solvent extract of G. tenax, MFAP= Methanolic fraction of A.pannosum, MFGT=Methanolic fraction of G. tenax].

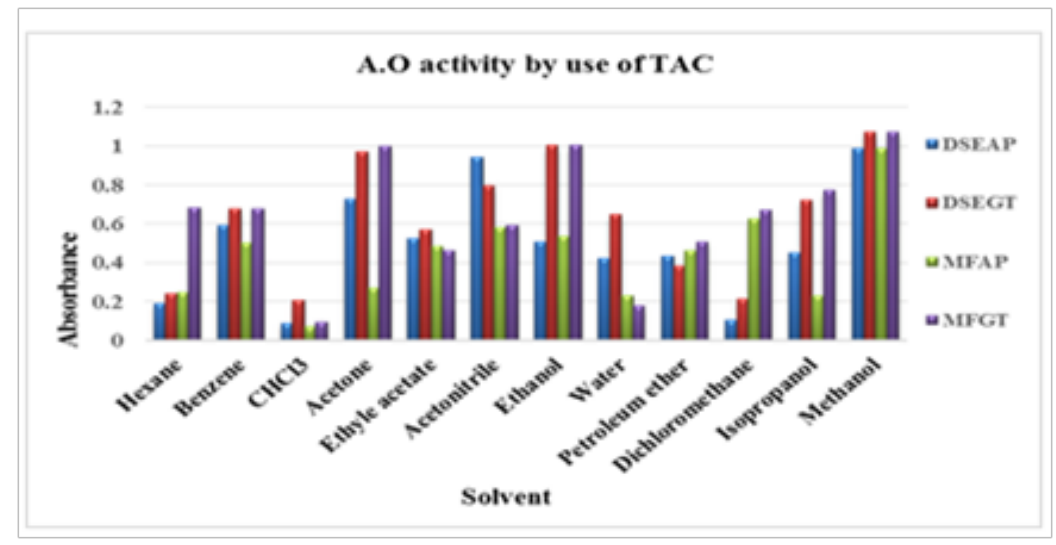

Figure 13 Comparison between different solvent extract and its methanolic fraction by TAC method. 


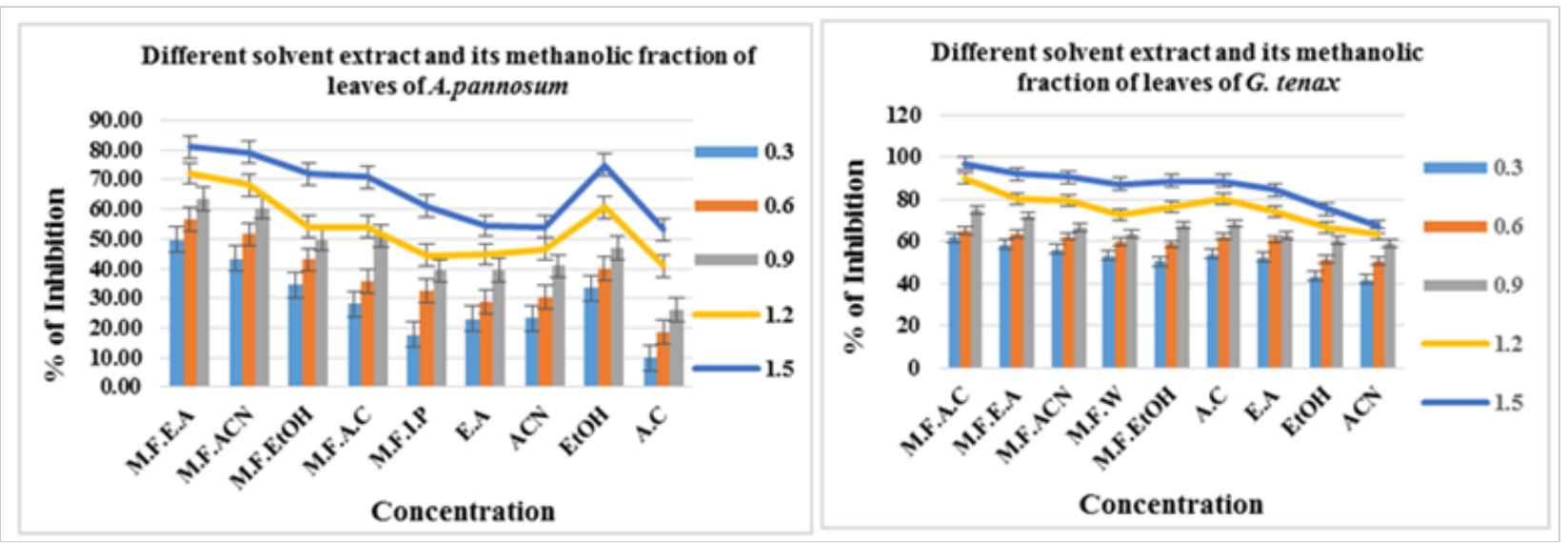

Figure I $4 \%$ of Inhibition of different conc. of plant extracts for free radical scavenging activity by DPPH radical. Extracts: M.F.E.A=Methanolic fraction of ethyl acetate, M.F.ACN=Methanolic fraction of acetonitrile, M.F.EtOH=Methanolic fraction of ethanol, M.F.A.C=Methanolic fraction of acetone, M.F.I.P=Methanolic fraction of isopropanol, E.A=Ethyl acetate, $\mathrm{ACN}=$ Acetonitrile, $\mathrm{EtOH}=$ Ethanol, $\mathrm{A} . \mathrm{C}=$ Acetone.

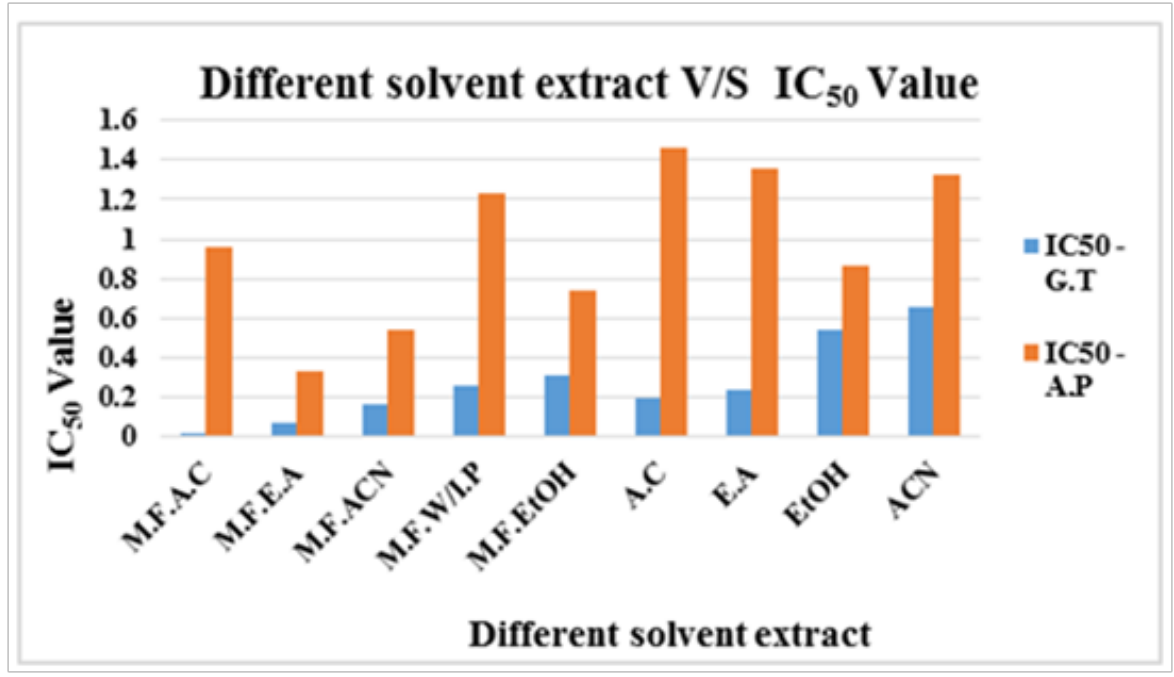

Figure I 5 IC50 of DPPH scavenging activities in various leaf extracts from two plant of A. pannosum and G. tenax.

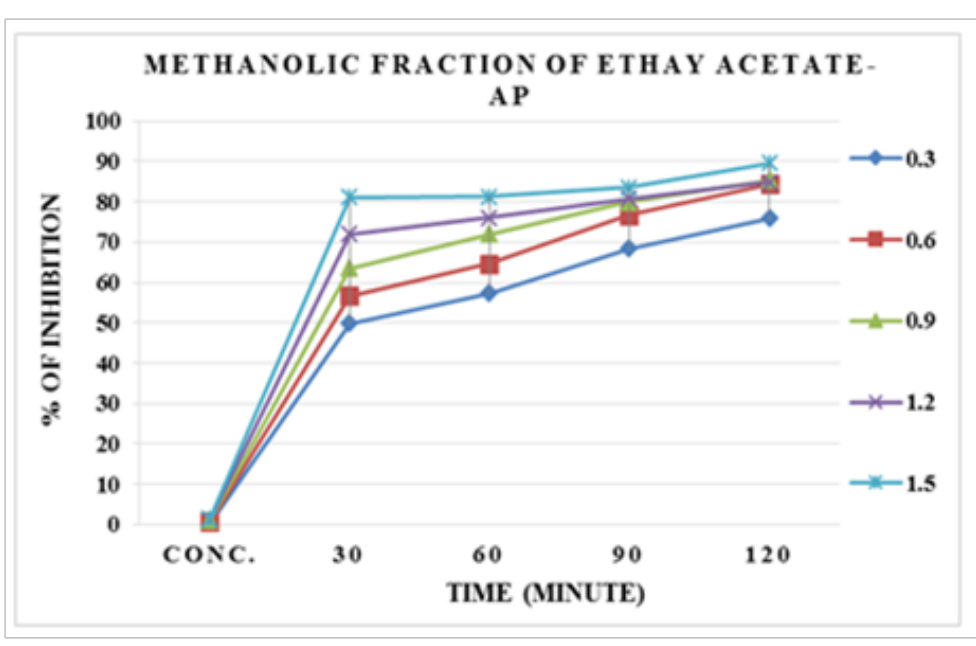

Figure 16 Effect of time on the scavenging of methanolic fraction of Ethyl acetate-AP. 


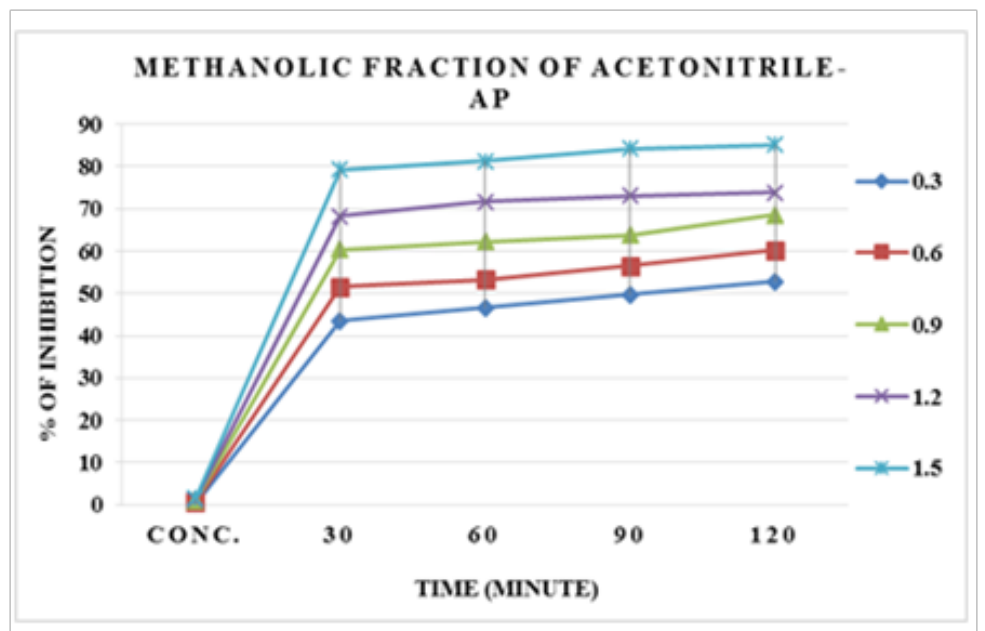

Figure 17 Effect of time on the scavenging of methanolic fraction of acetonitrile-AP.

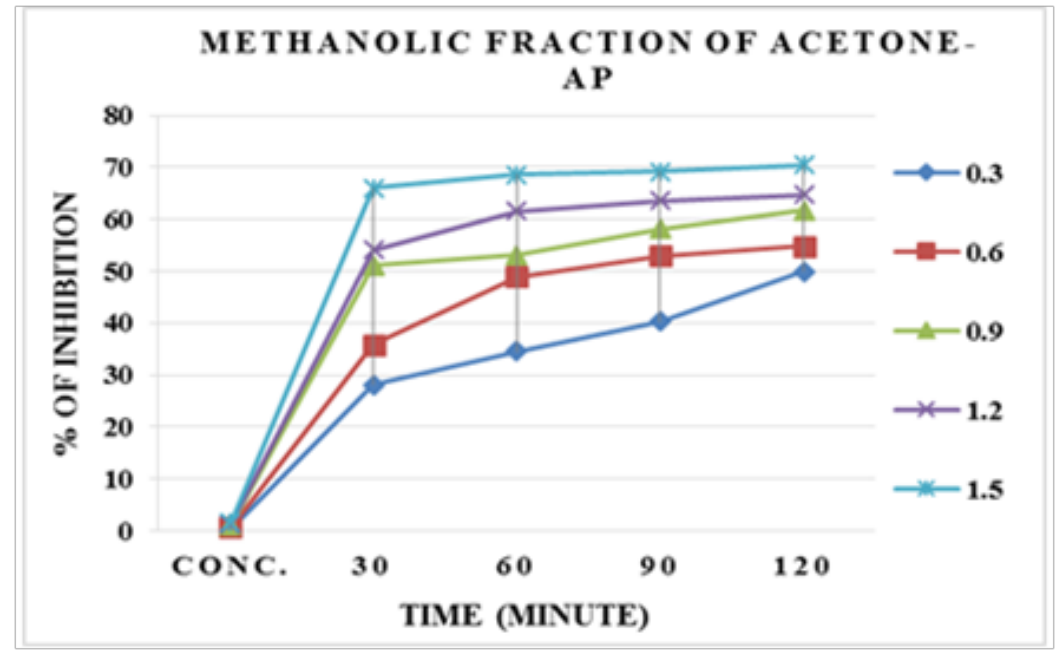

Figure I 8 Effect of time on the scavenging of methanolic fraction of Acetone-AP.

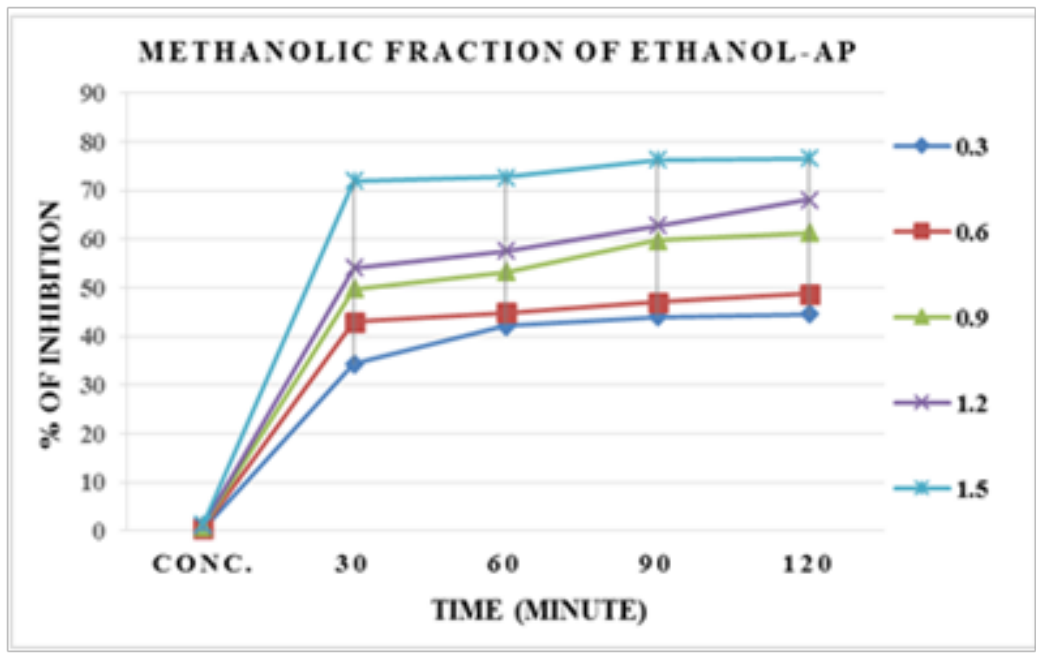

Figure 19 Effect of time on the scavenging of methanolic fraction of ethanol-AP. 


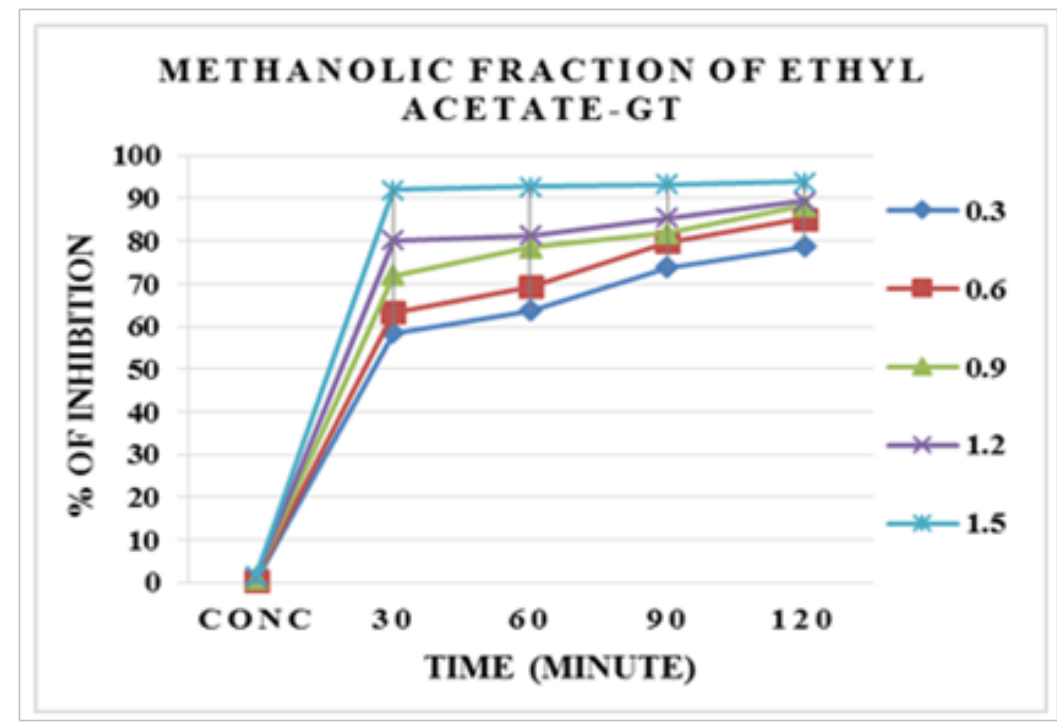

Figure 20 Effect of time on the scavenging of methanolic fraction of Ethyl acetate-GT.

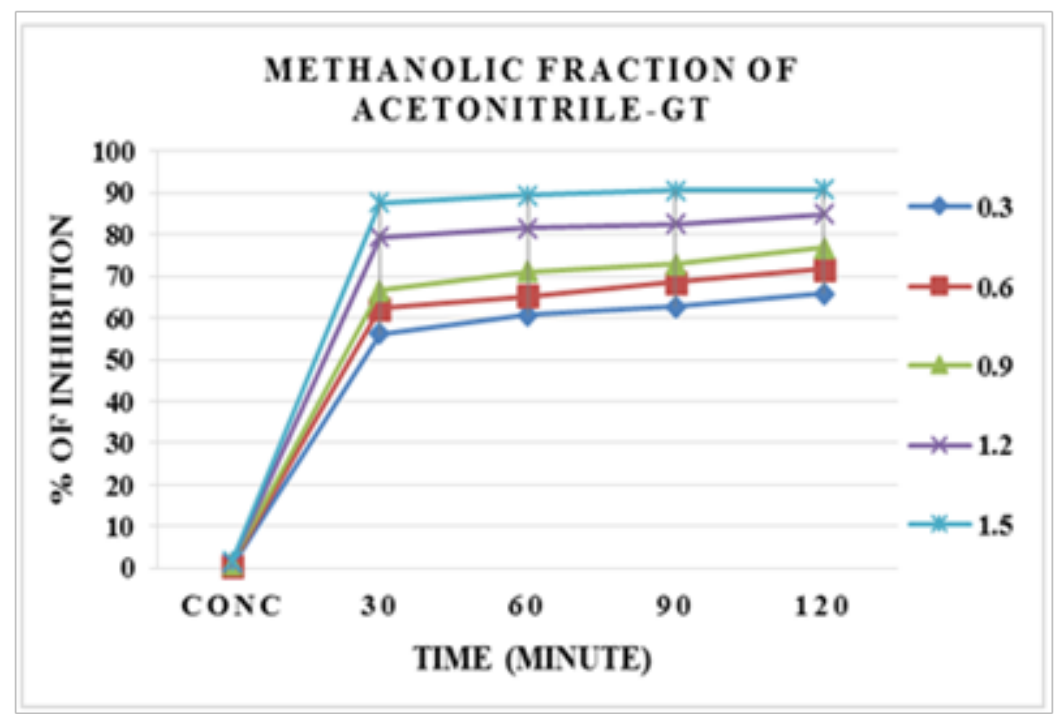

Figure 2I Effect of time on the scavenging of methanolic fraction of Acetonitrile-GT.

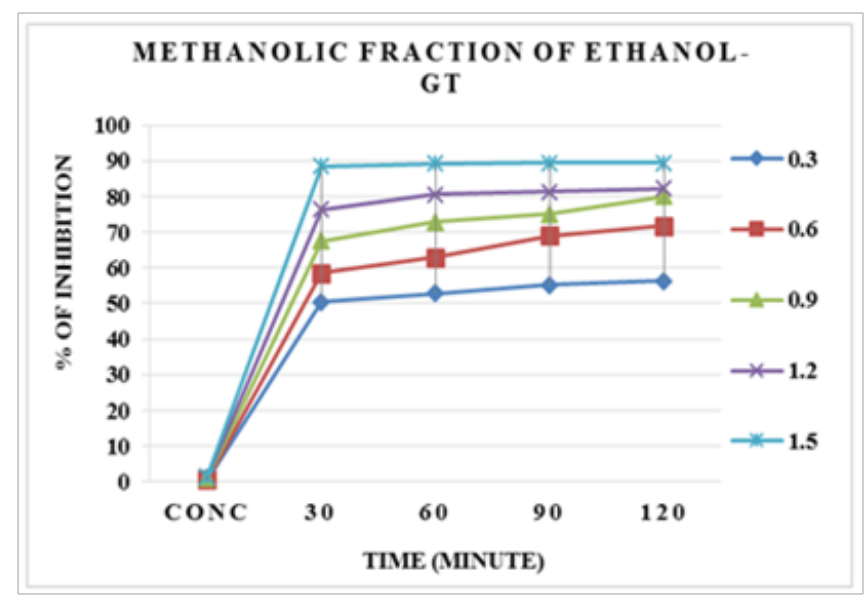

Figure 22 Effect of time on the scavenging of methanolic fraction of Ethanol-GT. 


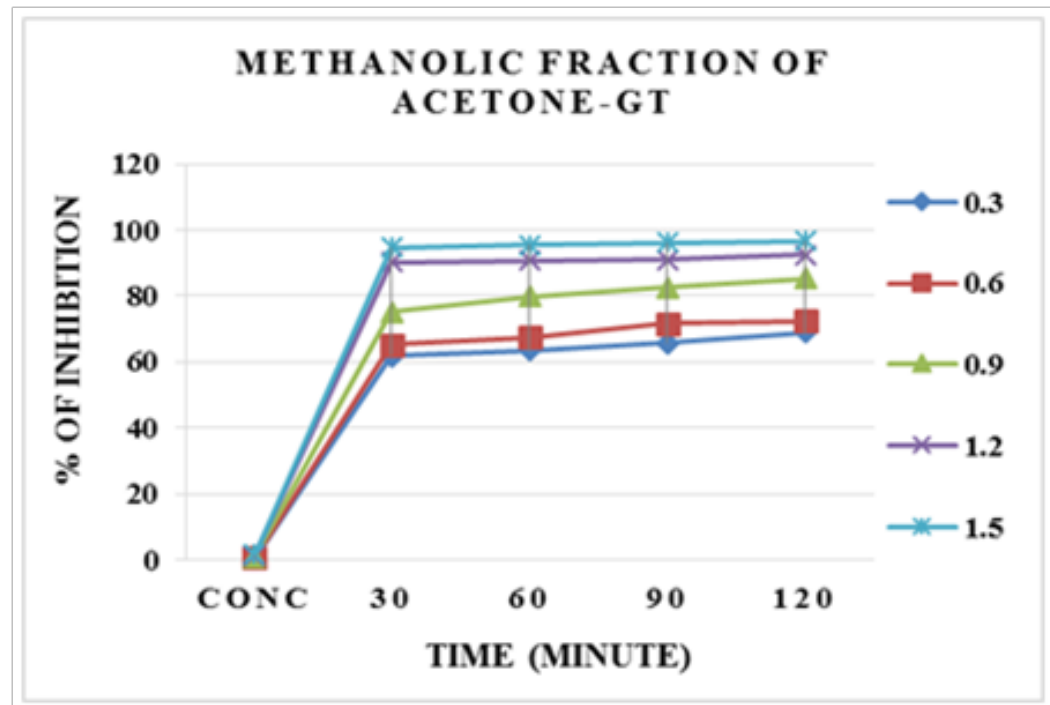

Figure 23 Effect of time on the scavenging of methanolic fraction of Acetone-GT.

Table I IC 50 of DPPH scavenging activities in various leaf extracts from two plants of A. pannosum and G. Tenax

\begin{tabular}{llll}
\hline Sr. No. & Extracts & $\mathbf{I C}_{\mathbf{5 0}}$-G.T & $\mathbf{I C}_{\mathbf{5 0}}$-A.P \\
\hline 1 & M.F.A.C & 0.023 & 0.959 \\
2 & M.F.E.A & 0.072 & 0.338 \\
3 & M.F.ACN & 0.167 & 0.541 \\
4 & M.F.W/I.P & 0.259 & 1.234 \\
5 & M.F.EtOH & 0.317 & 0.739 \\
6 & A.C & 0.193 & 1.46 \\
7 & E.A & 0.242 & 1.354 \\
8 & EtOH & 0.541 & 0.866 \\
9 & ACN & 0.652 & 1.323
\end{tabular}

Table 2 A.O activity of different solvent leaf extract of A. pannosum and G. tenax by using different types of three methods DPPH,TAC and ABTS

\begin{tabular}{lllllll}
\hline \multirow{2}{*}{ Solvent name } & \multicolumn{2}{l}{ DPPH $(\%$ SCN) } & \multicolumn{2}{c}{ TAC (absorbance) } & \multicolumn{2}{c}{ ABTS (\% SCN) } \\
\cline { 2 - 7 } Hexane & AP & GT & AP & GT & AP & GT \\
Benzene & 9.83 & 21.76 & 0.19 & 0.238 & 26.14 & 52.14 \\
CHCl3 & 2.51 & 9.31 & 0.592 & 0.674 & 58.14 & 27.86 \\
Acetone & 7.22 & 9.83 & 0.091 & 0.205 & 1.86 & 20.43 \\
Ethyl acetate & 40.79 & 82.64 & 0.725 & 0.971 & 46 & 82 \\
Acetonitrile & 70.19 & 70.4 & 0.939 & 0.794 & 66.43 & 85.29 \\
Ethanol & 78.66 & 78.45 & 0.505 & 1.001 & 45.57 & 86.57 \\
Water & 4.81 & 11.4 & 0.42 & 0.648 & 68.71 & 69.43 \\
Petro. ether & 7.43 & 31.9 & 0.434 & 0.381 & 64.57 & 26.29 \\
Isopropanol & 16 & 16.84 & 0.451 & 0.723 & 26.29 & 60.29 \\
Methanol & 32.64 & 49.69 & 0.989 & 1.069 & 66.29 & 82.57 \\
\hline
\end{tabular}


Table 3 Antioxidant activity of A. pannosum and G. tenax plant leaves methanolic fraction extract of different solvents by DPPH and TAC (PM) method

\begin{tabular}{lllll}
\hline \multirow{2}{*}{ Solvent name } & \multicolumn{2}{c}{ DPPH (\% SCN) } & \multicolumn{2}{l}{ TAC (absorbance) } \\
\cline { 2 - 5 } Hexane & MFAP & MFGT & MFAP & MFGT \\
Benzene & 61.92 & 68.1 & 0.245 & 0.682 \\
CHCl3 & 51.78 & 50.73 & 0.501 & 0.678 \\
Acetone & 31.8 & 42.26 & 0.072 & 0.096 \\
Ethyl acetate & 73.95 & 90.48 & 0.27 & 0.999 \\
Acetonitrile & 81.38 & 89.12 & 0.578 & 0.592 \\
Ethanol & 78.66 & 78.45 & 0.535 & 1.003 \\
Water & 0.21 & 87.76 & 0.23 & 0.177 \\
Petroleum ether & 62.66 & 73.01 & 0.46 & 0.508 \\
Isopropanol & 67.36 & 35.77 & 0.229 & 0.771 \\
\hline
\end{tabular}

Table 4 Effect of time on Scavenging of methanolic fraction extracts by use of DPPH Method

\begin{tabular}{|c|c|c|c|c|c|c|c|c|c|c|c|c|c|c|c|c|}
\hline \multicolumn{17}{|c|}{ Abutilon Pannosum } \\
\hline \multirow[b]{2}{*}{ Conc. } & \multicolumn{4}{|c|}{ MFE of ethyl acetate } & \multicolumn{4}{|c|}{ MFE of acetonitrile } & \multicolumn{4}{|c|}{ MFE of ethanol } & \multicolumn{4}{|c|}{ MFE of acetone } \\
\hline & 30 & 60 & 90 & 120 & 30 & 60 & 90 & 120 & 30 & 60 & 90 & 120 & 30 & 60 & 90 & 120 \\
\hline 0.3 & 49.8 & 57.2 & 68.4 & 75.8 & 43.4 & 46.5 & 49.7 & 52.8 & 34.4 & 42.1 & 44 & 44.6 & 28.1 & 34.6 & 40.3 & 49.9 \\
\hline 0.6 & 56.7 & 64.6 & 76.7 & 84.3 & 51.5 & 53.2 & 56.5 & 60.2 & 43 & 44.9 & 47 & 48.8 & 35.8 & 49 & 52.9 & 54.8 \\
\hline 0.9 & 63.4 & 72 & 80 & 85.3 & 60.4 & 62.3 & 63.7 & 68.5 & 49.7 & 53.2 & 59.8 & 61.4 & 51 & 53.1 & 58.2 & 61.7 \\
\hline 1.2 & 72 & 76 & 80.7 & 84.8 & 68.2 & 71.7 & 73.1 & 73.9 & 54 & 57.6 & 62.8 & 68.1 & 54.1 & 61.6 & 63.6 & 64.8 \\
\hline 1.5 & 81.1 & 81.3 & 83.6 & 89.6 & 79.2 & 81.3 & 84.3 & 85.2 & 72 & 72.7 & 76.3 & 76.6 & 66.1 & 68.6 & 69.2 & 70.5 \\
\hline \multicolumn{17}{|c|}{ Grewia tenax } \\
\hline & \multicolumn{4}{|c|}{ MFE of ethyl acetate } & \multicolumn{4}{|c|}{ MFE of acetonitrile } & \multicolumn{4}{|c|}{ MFE of ethanol } & \multicolumn{4}{|c|}{ MFE of acetone } \\
\hline Conc. & 30 & 60 & 90 & 120 & 30 & 60 & 90 & 120 & 30 & 60 & 90 & 120 & 30 & 60 & 90 & 120 \\
\hline 0.3 & 58.5 & 63.6 & 73.9 & 78.7 & 56.1 & 60.7 & 62.7 & 65.8 & 50.5 & 52.8 & 55.3 & 56.3 & 61.7 & 63.4 & 65.7 & 68.9 \\
\hline 0.6 & 63.3 & 69.4 & 79.7 & 85.2 & 62.3 & 65.1 & 68.6 & 71.6 & 58.6 & 62.9 & 69.1 & 71.7 & 65.1 & 67.4 & 71.7 & 72.3 \\
\hline 0.9 & 72 & 78.6 & 81.8 & 88.3 & 66.5 & 71.1 & 72.8 & 76.9 & 67.5 & 72.8 & 75.1 & 80.1 & 75 & 79.9 & 82.4 & 85.2 \\
\hline 1.2 & 80.2 & 81.3 & 85.4 & 89.3 & 79.4 & 81.6 & 82.5 & 84.8 & 76.3 & 80.6 & 81.3 & 82.2 & 90.1 & 90.6 & 91 & 92.4 \\
\hline 1.5 & 92 & 92.7 & 93.3 & 93.9 & 87.7 & 89.5 & 90.5 & 90.7 & 88.6 & 89.4 & 89.5 & 89.5 & 94.7 & 95.5 & 96.1 & 96.7 \\
\hline
\end{tabular}

\section{Conclusion}

Physiochemical properties of the sample are very important for analyzing antioxidant properties. The purpose of the present study is to explore the antioxidant potential of different solvent extracts and its methanolic fractions of $A$. pannosum and $G$. tenax leaves powder were made using the successive soxhlet extraction method using various solvents with different polarity. Great levels of antioxidant activity (AOA) were detected in $G$. tenax leaf as compared to $A$. pannosum leaf indicating that the $G$. tenax leaf may serve as an excellent source of natural antioxidants. During comparison between different solvent extract and its methanolic fraction of AP and GT plant leaves by DPPH and TAC (PM) method. In the DPPH assay methanolic fraction of different solvent extract had higher AOA value compare to different solvent extract and TAC assay different solvent extract exposed higher adsorption compare to its methanolic fraction except of $n$-hexane, petroleum ether and dichloromethane. The $\%$ of free radical scavenging increase with increase concentration of extract as well as time. The Concentration expressed as $\mathrm{IC}_{50}$ values. $\mathrm{IC}_{50}$ values are inversely proportional to the antioxidant activity of plant extracts. As per DPPH assay result \% of free radical scavenging increase with decreases $\mathrm{IC}_{50}$ values and increase time as certain limit. Therefore, it can be definite that both plant extracts possess strong antioxidant activity. According to the above results we can conclude 
that the antioxidant capacity of sample extract was dependent on the type of solvent, concentration of the extract, AOA method and also reaction time. The outcomes of this work are useful for further research to identify, isolate and characterize the exact compound which is accountable for greater antioxidant activity.

\section{Acknowledgements}

None.

\section{Conflict of interest}

The author declares no conflict of interest.

\section{References}

1. Brown JE, Rice Evans CA. Luteolin-Rich artichoke extract protect low density lipoprotein from oxidation in vitros. Free Radic Res. 1998;29(3):247-255.

2. Dold T, Cocks M. A succulent herbal-the medicinal and cultural use of some succulent plants traded in the Eastern cape Province of South Africa. Cactus and Succulent J. 2001;73:141-145.

3. Ames BN, Shigenag MK, Hagen TM. Oxidants, antioxidants, and the degenerative diseases of aging. Proc Natl Acad Sci USA. 1993;90(17):7915-7922.

4. Yang CS, Landau JM, Huang MT, et al. Inhibition of carcinogenesis by dietary polyphenolic compounds. Annual Rev Nutr. 2001;21:381-406.

5. Valko M, Leibfritz $\mathrm{M}$, Cronin $\mathrm{M}$, et al. Free radicals and antioxidants in normal physiological functions and human disease. Int J Biochem Cell Biol. 2007;39(1):44-84.

6. Marchioli R, Schweiger C, Levantesi G, et al. Antioxidant vitamins and prevention of cardiovascular disease: epidemiological and clinical trial data. Lipids. 2001;36:S53-63.

7. Pisochi AM, Negulescu GP. Methods for total antioxidants activity determination: A review. Biochemistry and Analytical Biochemistry. 2011;1:1-10.

8. Prior RL, Wu X, Schaich K. Standardized methods for the determination of antioxidant capacity and phenolic in foods and dietary supplements. J Agri Food Chem . 2005;53(10):4290-4302.

9. Alonso AM, Dominguez C, Guillen DA, et al. Determination of antioxidant power of red and white wines by a new electrochemical method and its correlation with polyphenolic content. J Agric Food Chem. 2002;50(11):3112-3115.

10. Ahlem R, Souad I, Béatrice B, et al. Total Phenolic, Total Flavonoid, Tannin Content, and Antioxidant Capacity of Halimium halimifolium (Cistaceae). Journal of Applied Pharmaceutical Science. 2015;5(01):052-057.

11. Kahkonen MP, Hopia AI, Vuorela HJ, et al. Antioxidant activity of plant extracts containing phenolic compounds. J Agric Food Chem. 1999;47(10):3954-3962.

12. Grigonisa D, Venskutonisa PR, Sivikb B, et al. Comparison of different extraction techniques for isolation of antioxidants from sweet grass (Hierochloë odorata). The Journal of Supercritical Fluids. 2005;33(3):223-233.

13. Fradovich I. Biological effects of the superoxide radical. Arch Biochem Biophy. 1986;247(1):1-11.

14. Droge W. Free radicals in the physiological control of cell function. Physiol Rev. 2002;82(1):47-95.

15. Kato K, Terao S, Shimamoto N, et al. Studies on scavengers of active oxygen species. 1. Synthesis and biological activity of 2-O-alkylascorbic acids. J Med chem. 1988;31(4):793-798.

16. Blois MS. Antioxidant determinations by the use of a stable free radical. Nature. 1958;181:1199-1200.

17. Halliwell B, Gutteridge JMC. Free radicals, ageing and disease. Free radicals in Biology and Medicine. 2nd ed. Oxford, USA: Clarendron Press; 1985. p. 279-315.

18. Ohkawa H, Ohisini N, Yagi K. Assay for lipid peroxides in animal tissues by thiobarbituric acid reaction. Anal Biochem. 1979;95(2):353-358.

19. Larson RA. The antioxidants of higher plants. Phytochem. 1988;27(4):969-978.

20. Daivies KJ. Oxidative stress, antioxidant defenses, and damage removal, repair, and replacement systems. IUBMB Life. 2000;50(4-5):279-289.

21. Re R, Pellegrini N, Proteggente A, et al. Antioxidant activity applying an improved ABTS radical cation decolorization assay. Free Radical Bio Med. 1999;26(9-10):1231-1237.

22. Sahreen S, Khan MR, Khan RA. Evaluation of antioxidant activities of various solvent extracts of Carissa opaca fruits. Food Chem. 2010;122(4):1205-1211.

23. Prieto P, Pineda M, Aguilar M. Spectrophotometric quantitation of antioxidant capacity through the formation of a phosphomolybdenum complex: Specific application to the determination of Vitamin E1. Anal Biochem. 1999;269(2):337341.

24. Khan RA, Khan MR, Sahreen S. Assessment of flavonoids contents and in vitro antioxidant activity of Launaea procumbens. Chem Central J. 2012;6:43.

25. Tiwari P, Kumar B, Kaur M, et al. Phytochemical screening and extraction: A review. International Pharmaceutical sciencia. 2011;1(1):98-106.

26. Rice Evans CA, Miller NJ, Bowell PG, et al. The relative antioxidant activities of plant-derived polyphenolic flavonoids. Free Radical Res. 1995;22(4):375-383.

27. Jan S, Khan MR, Rashid U, et al. Assessment of antioxidant potential, total phenolics and flavonoids of different solvent fractions of Monotheca Buxifolia fruit. Osong Public Health Res Perspect. 2013;4(5):246-254.

28. Pérez Jiménez J, Saura Calixto F. Effect of solvent and certain food constituents on different antioxidant capacity assays. Food Research International. 2006;39(7):791-800. 
29. Prieto P, Pineda M, Aguilar M. Spectrophotometric quantitation of antioxidant capacity through the formation of a Phosphomolybdenum complex: specific application to the determination of vitamin E. Analytical Biochemistry. 1999;269(2):337-341.

30. Mashwani Z, Khan MA, Irum S, et al. Antioxidant potential of root bark of Berberis lycium Royle from Galliyat, western Himalaya, Pakistan. Pak J Bot. 2013;45:231-234.

31. Wang M, Li J, Rangarajan M, et al. Antioxidative phenolic compounds from Sage (Salvia officinalis). J Agric Food Chem. 1998;46(12):4869-4873.

32. Bortolomeazzi R, Verardo G, Liessi A, et al. Formation of dehydrodiisoeugenol and dehydrodieugenol from the reaction of isoeugenol and eugenol with DPPH radical and their role in the radical scavenging activity. Food Chem. 2010;118(2):256-265.

33. Oszmianski J, Wojdylo A, Lamer Zarawska E, et al. Antioxidant tannins from Rosaceae plant roots. Food Chemistry. 2007;100(2):579-583.

34. Gil MI, Tomas Barberan FA, Hess Pierce B, et al. Antioxidant activity of pomegranate juice and its relationship with phenolic composition and processing. J Agric Food Chem. 2000;48(10):4581-4589.

35. Ravisankar N, Sivaraj C, Seeni S, et al. Antioxidant activites and phytochemical analysis of methanol extract of leaves of hypericum hookerianum. Int J Pharm Pharm Sci. 2014;6(4):456460.

36. Matkowski A, Tasarz P, Szypuła E. Antioxidant activity of herb extracts from five medicinal plants from Lamiaceae, subfamily Lamioideae. J Med Plants Res. 2008;2(1):321-330.

37. Apak R, Güçlü K, Ozyürek M, et al. Novel total antioxidant capacity index for dietary polyphenols and vitamins $\mathrm{C}$ and $\mathrm{E}$, using their cupric ion reducing capability in the presence of neocuproine: CUPRAC method. J Agric Food Chem. 2004;52(26):7970-7981.

38. Wolfenden BS, Willson RL. Radical-cations as reference chromogens in kinetic studies of one-electron transfer reactions: pulse radiolysis studies of [2, 2-azinobis-(3-ethylbenzthiazoline6-sulphonate)]. J Chem Soc Perkin Trans. 1982;2(7):805-812.

39. Julkunen-Tiito R. Phenolic constituents in the leaves of northern willows, methods for the analysis of certain phenolics. $J$ Agric Food Chem. 1985;33(2):213-217.

40. Marinova EM, Yanishlieva N. Antioxidative activity of extracts from selected species of the family Lamiaceae in sunflower oil. Food Chem. 1997;58(3):245-248.

41. Upadhyay R, Singh SP, Jha A, et al. Appropriate solvents for extracting total phenolic, flavonoids and ascorbic acid from different kinds of millets. J Food Sci Technol. 2013;52(1):472478 .

42. Singh M, Jha A, Kumar A, et al. Influence of the solvents on the extraction of major phenolic compounds (punicalagin, ellagic acid and gallic acid) and their antioxidant activities in pomegranate aril. J Food Sci Technol. 2014;51(9):2070-2077.
43. Mounir Mansori. Evaluation of antioxidant capacity of methanol extract and its solvent fractions obtained from four moroccan macro algae species. European Scientific Journal edition. 2014;10(15):1857-7881.

44. Gaulejac NS, Provost C, Vivas N. Comparative study of polyphenol activities assessed by different methods. J Agric Food Chem. 1999;47(2):425-431.

45. Dhalwal K, Deshpande YS, Purohit AP, et al. Evaluation of the antioxidant activity of Sida cordifolia. J Pharm Biol. 2005;4(9)3:754-761.

46. Cao G, Sofic E, Prior R. Antioxidant capacity of tea and common vegetables. J Agriculture Food Chem. 1996;4(11):3426-3431.

47. Thaipong K, Boonprakob U, Crosby K, et al. Comparison of ABTS, DPPH, FRAP, and ORAC assays for estimating antioxidant activity from guava fruit extracts. J Food Comp Anal. 2006;19(6-7):669-675.

48. Kaur R, Arora S, Singh B. Antioxidant activity of the phenol rich fractions of leaves of Chukrasia Tabularis A. Juss Bioresource Technology. 2008;99(16):7692-7698.

49. Chaovanalikit A, Wrolstad RE. Total anthocyanins and total phenolics of fresh and processed cherries and their antioxidant properties. J Food Sci. 2004;69(1):67-72.

50. Masoko P, Gololo SS, Mokgotho MP, et al. Evaluation of the antioxidant, antibacterial, and antiproliferative activities of the acetone extract of the roots of Senna Italica (Fabaceae). Afr $J$ Tradit Complement Altern Med. 2010;7(2):138-148.

51. Scherer R, Godoy HT. Antioxidant activity index (AAI) by the 2, 2-diphenyl-1-picrylhydrazyl method. Food Chem. 2009; 112(3):654-658.

52. Osborn HT, Akoh CC. Effects of natural antioxidants on ironcatalysed lipid oxidation of structured lipid-based emulsions. $J$ Am Oil Chem Soc. 2003;80(9):847-852.

53. Pérez-Jiménez J, Arranz S, Tabernero M, et al. Updated methodology to determine antioxidant capacity in plant foods, oils and beverages: Extraction, measurement and expression of results. Food Research International. 2008;4(3):274-285.

54. Yen G, Chen H. Antioxidant activity of various tea extract in relation to their antimutagenicity. Journal of Agricultural and Food Chemistry. 1995;43(1):27-32.

55. Chan SW, Wan Aida WM, Lee CY, et al. Optimisation of extraction conditions for phenolic compounds from limau purut (Citrus hystrix) peels. Journal of International Food Research. 2009;16(2):203-213.

56. Chew KK, Ng SY, Thoo YY, et al. Effect of ethanol concentration, extraction time and extraction temperature on the recovery of phenolic compounds and antioxidant capacity of Centella asiatica extracts. Journal of International Food Research. 2011;18(2):571-578. 